\title{
A Power Management IC Used for Monitoring and Protection of Li-Ion Battery Packs
}

\author{
Yunqiang Hao $\mathbb{D}^{1}{ }^{1}$ Dongbai Yi, ${ }^{2}$ Xiaowei Zhang $\mathbb{D}^{1},{ }^{1}$ Wenxin Yu, ${ }^{1}$ Jianxiong Xi, \\ and Lenian $\mathrm{He} \mathbb{D i D}^{1}$ \\ ${ }^{1}$ College of Information Science \& Electronic Engineering Zhejiang University, Hangzhou 310007, China \\ ${ }^{2}$ Zhuhai Edgeless Semiconductor Co., Ltd., Zhuhai 519000, China \\ Correspondence should be addressed to Lenian He; helenian@zju.edu.cn
}

Received 13 October 2020; Revised 21 March 2021; Accepted 26 March 2021; Published 9 April 2021

Academic Editor: Yajie Qin

Copyright (C) 2021 Yunqiang Hao et al. This is an open access article distributed under the Creative Commons Attribution License, which permits unrestricted use, distribution, and reproduction in any medium, provided the original work is properly cited.

\begin{abstract}
A power management system is a critical component of the system which needs Li-ion battery packs for power supply. This paper proposes a fully integrated, high-precision, and high-reliability Integrated Circuit (IC) for the power management system of Li-ion battery packs. It has full protection circuits including overvoltage, overtemperature, and overcurrent circuits with measuring voltage accuracy of $0.2 \mathrm{mV}$ and a 15-bit internal Successive Approximation Register (SAR) Analog-to-Digital Converter (ADC). This IC is designed to protect the system automatically and measure the battery cells' voltage, temperature, and charging or discharging current with high precision. It also provides an $\mathrm{I}^{2} \mathrm{C}$ interface to communicate with an external Microcontroller Unit (MCU), making it achievable to perform battery cells' voltage balancing and SOC estimation with $0.1 \%$ estimation accuracy in an hour.
\end{abstract}

\section{Introduction}

To ensure efficient and secure operation of the system with Li-ion battery packs, a system which can intelligently monitor and protect the battery system in real time is necessary [1]. As battery manufacturing technology matures, a battery's volume and voltage are getting increasingly precise, which asks a much more precise and stable management system. Also, for the large equipment, the Li-ion battery pack always contains a huge number of cells, meaning that the system must have high voltage tolerance. The requirements including higher precision, higher stability, and higher voltage tolerance put forward a great challenge for the design of power management system IC. There are many relevant ICs available nowadays [2]. However, these ICs are generally too expensive and can hardly meet all the possible requirements, such as high precision, high stability, high voltage tolerance, and high integration level. For example, [3] presents an IC which has a 16-bit delta-sigma ADC, achieving $2.2 \mathrm{mV}$ total measurement accuracy. [4] presents an IC which can also achieve highly accurate cell voltage measurements. These products cannot drive the power MOSFET, which means they cannot cut off the charging or discharging path without extra devices. Thus, when an abnormal condition occurs, they need the external MCU to perform protection actions, which makes the application circuit much more complicated. Some other modern products also have some deficiencies.

In this paper, a fully integrated, high-reliability, and highprecision power management system IC for the electric system with Li-ion battery packs is proposed. It contains protection circuits, internal Successive Approximation Register (SAR) Analog-to-Digital Converter (ADC), power MOSFETs' driving circuit, and $\mathrm{I}^{2} \mathrm{C}$ interface. The IC can sample battery cells' voltage, temperature signals, and current's magnitude with $0.2 \mathrm{mV}$ accuracy. It can also detect abnormal conditions including overvoltage, overtemperature, and charging or discharging overcurrent. Besides, the IC can drive the power MOSFETs in the charging and discharging path, thus controlling whether the system is connected to 
the charger or the load. With the $\mathrm{I}^{2} \mathrm{C}$ interface, this IC can work with external MCU, achieving functions like cell balancing and SOC estimation.

This paper is divided into six sections. Section 2 provides an overview of the IC's architecture. Sections 3 demonstrates some considerations in the design of high-precision sampling circuit to ensure the accuracy of controlling. Section 4 gives general descriptions of protection circuit design and the algorithms of the Li-ion battery pack management system with this IC in application. Section 5 provides some test results. Section 6 summarizes the IC's functions and innovations and gives the prospects.

We note that a shorter conference version of this paper appeared in Hao et al. [5]. Our initial conference paper focused on the protection and security of the system and did not address the detailed realization of the highprecision sampling of battery voltages and current amplitude. This manuscript addresses the realization of sampling methods using an internal high-precision SAR ADC and shows more experimental results.

The detailed performance specifications are shown in Table 1. The given numbers are default values, and users can choose other values by writing the registers.

\section{Chip Architecture}

The IC contains protection circuits, internal SAR ADC, power MOSFETs' driving circuit, and $\mathrm{I}^{2} \mathrm{C}$ interface, as shown in Figure 1. It can be directly used in the power management systems, providing cell voltage input and power MOSFET drive output. It also has some other signal input pins like external temperature sampling, wake-up sensor, and output pins like cell balance control output CBN. Figure 2 shows the diagram of the complete IC. The IC is designed to monitor series connected cells with high voltage tolerance. All the battery cells are connected to the input of level shifters inside the IC, so the voltage intervals at a high level will be shifted into an interval of $0 \sim 5 \mathrm{~V}$. Then, these voltages are divided by two, turning into the voltage interval of $0 \sim 2.5 \mathrm{~V}$. After the above operation, the obtained voltage can be directly processed by the ADC and some other internal circuits, such as overvoltage protection circuit. The IC has some other voltages to be detected, such as the voltage generated by an external thermistor and a fixed resistor, the voltage generated by an internal bipolar transistor, and the voltage generated by a detecting resistor connected in series in the charge and discharge path. These voltages are separately used to detect the external temperature, the internal temperature, and the charging or discharging current magnitude. The IC detects abnormal conditions using these voltages and responds rapidly, thus ensuring the safety of the whole system in operation. The IC contains a 15-bit SAR ADC, which can operate self-calibration when the IC powers on. Cooperating with a multiplexer, this internal SAR ADC can choose the certain signal channel to monitor cell voltages, current magnitudes, and external or internal temperature. MCU obtains data from this IC and uses this to perform required algorithms. In order to guarantee the balance of the battery pack and extend the battery's life, balancing circuitry is designed to perform passive cell voltage balancing, as shown in Figure 3. Besides, the IC has some digital blocks, including cell balancing control logic, power MOSFET control logic, registers, and abnormal conditions detecting logic including overcurrent, overvoltage, and overtemperature. Most modules of the IC are powered by a $5 \mathrm{~V}$ voltage generated inside by $\mathrm{LDO}$, while a $12 \mathrm{~V}$ voltage is generated to drive the power MOSFETs which control the ON-OFF of the charging and discharging path. The $3.3 \mathrm{~V}$ DC regulator output RGO and RGC are connected to an external power device to supply for MCU, thus making the MCU's current drawn from battery cells instead of this IC.

\section{Signal Sampling Circuit Design}

There are various voltage signals in which users may want to obtain. Thus, the ADC's input must have the ability to switch among these different voltage signal channels. As shown in Figure 1, different voltages can be chosen by a multiplexer, which is controlled by the $\mathrm{I}^{2} \mathrm{C}$ interface. When a certain voltage is selected to perform analog-digital conversion, the ADC is activated. After conversion is finished, the ADC's digital output is read by the $\mathrm{I}^{2} \mathrm{C}$ interface, and a multiplexer selects the next voltage signal automatically to start the next conversion cycle, thus achieving continuous conversion of all the voltage signals. There are three types of signals which need to be converted: battery cells' voltage, charging and discharging current, and temperature.

3.1. Battery Cells' Voltage Sampling. As shown in Figure 4, the $N^{\text {th }}$ battery cell is taken as an example. The voltage of this cell's anode is $V_{\text {cell }}(N)$, and the voltage of this cell's cathode is equal to the anode of the next cell $N-1$, which is $V_{\text {cell }}(N$ $-1)$. An op-amp is used to make $V_{X}=V_{\text {cell }}(N-1)$, thus generating a current in $2 R$ :

$$
I=\frac{V_{\text {cell }}(N)-V_{\text {cell }}(N-1)}{2 R} .
$$

This current flows in the resistor " $R$," generating a voltage which represents the battery cell " $N$ " voltage:

$$
V(N)=I \cdot R=\frac{V_{\text {cell }}(N)-V_{\text {cell }}(N-1)}{2} .
$$

The input range of the $\mathrm{ADC}$ is $0 \sim 2.5 \mathrm{~V}$, but the voltage of battery cells is usually around $4 \mathrm{~V}$. As mentioned before, cell voltages must be divided by two before being connected to the input of ADC. The voltage $V(N)$ can be converted directly by the internal SAR ADC.

However, these operational amplifiers used in the sampling circuit will extract a current $I_{b}$ from battery cells.

If there are 16 cells in total, when sampling the $16^{\text {th }}$ battery cell's voltage, considering that the op-amp in Figure 4 uses NMOS as input pairs, it takes $V_{\text {cell }}(15)$ as the power net and $V_{\text {cell }}(14)$ as the ground net. As shown in Figure 5, every battery cell is connected to the IC. However, parasitic resistance exists in every net. Considering the $14^{\text {th }}$ cell's anode, there is a current $I_{b}$ extracted from the $15^{\text {th }}$ cell's 
Table 1: Detailed design target.

\begin{tabular}{lc}
\hline Design target & Default \\
\hline Maximum battery cells & 16 \\
Total voltage range & $0 \sim 85 \mathrm{~V}$ \\
Overvoltage threshold & $4.25 \mathrm{~V}$ \\
Overcurrent threshold & $1.25 \mathrm{~V}(500 \mathrm{~m} \Omega$ sensing resistor recommended) \\
Protection time out & $200 \mu \mathrm{s}$ \\
\hline
\end{tabular}

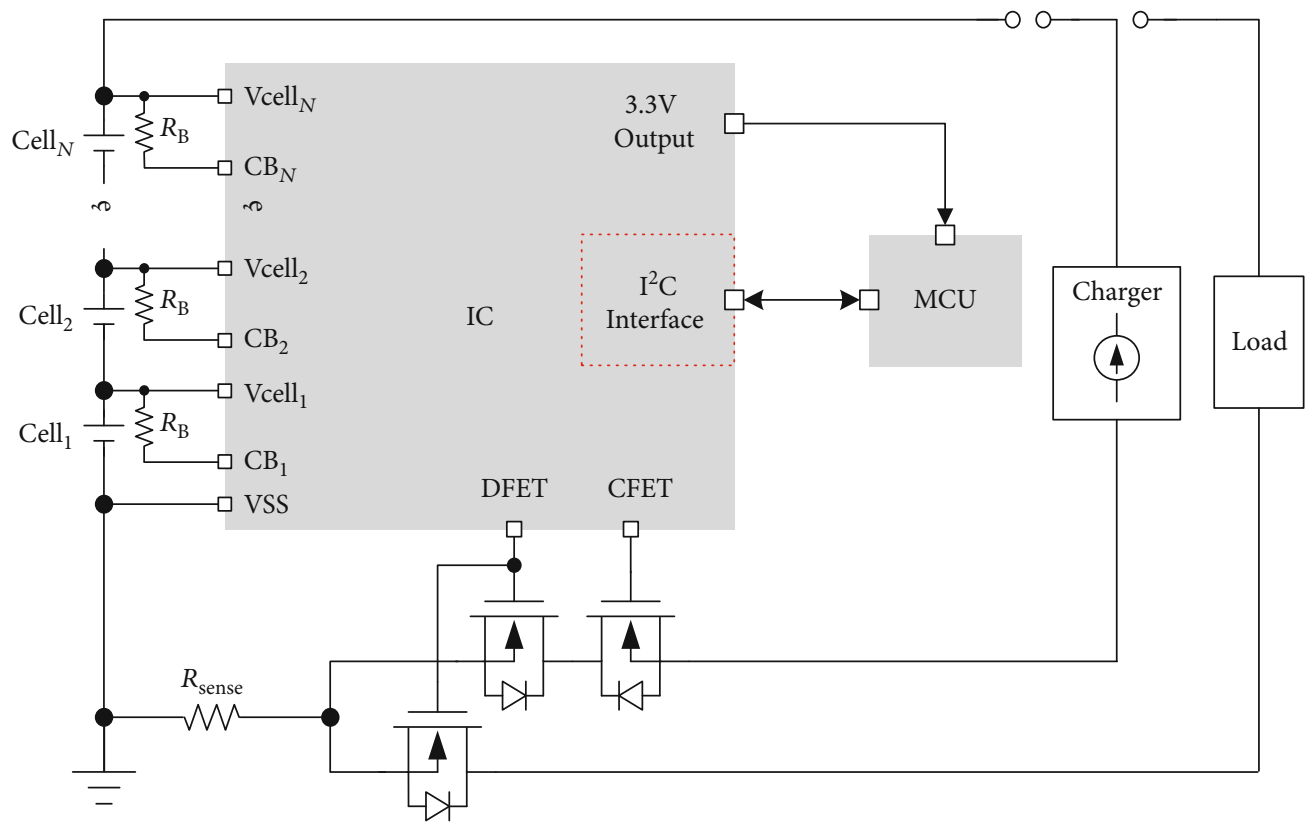

FIGURE 1: Diagram of the Li-ion battery pack management system.

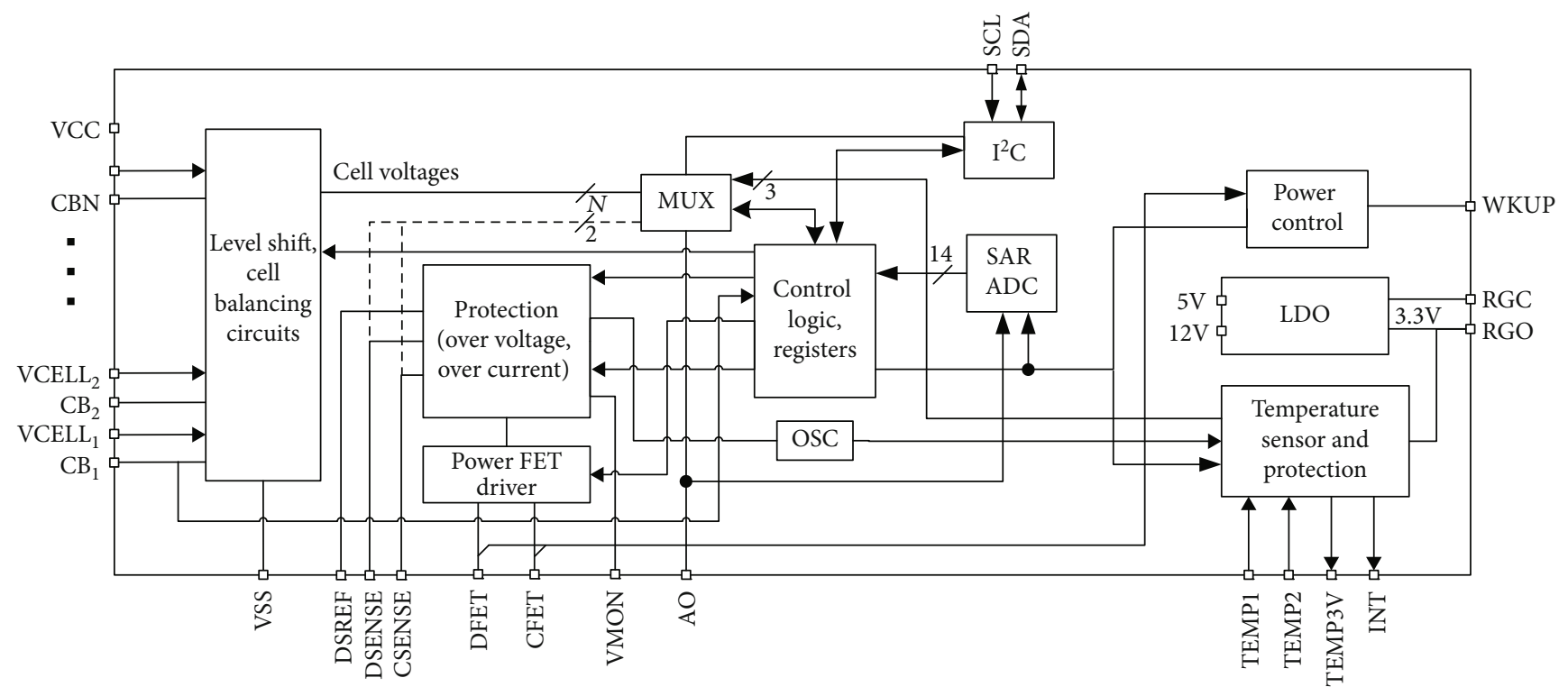

Figure 2: Diagram of the complete IC for the Li-ion battery management system.

sampling op-amp and a current $I_{b}$ injected by the $16^{\text {th }}$ cell's sampling op-amp, which can almost counterbalance. Yet, considering the $15^{\text {th }}$ cell's anode, there is only a current extracted by the $16^{\text {th }}$ cell's sampling op-amp. As shown by the black arrows in Figure 5, cell 1 cell 14's anode is extracted and injected a current $I_{b}$ simultaneously, which 


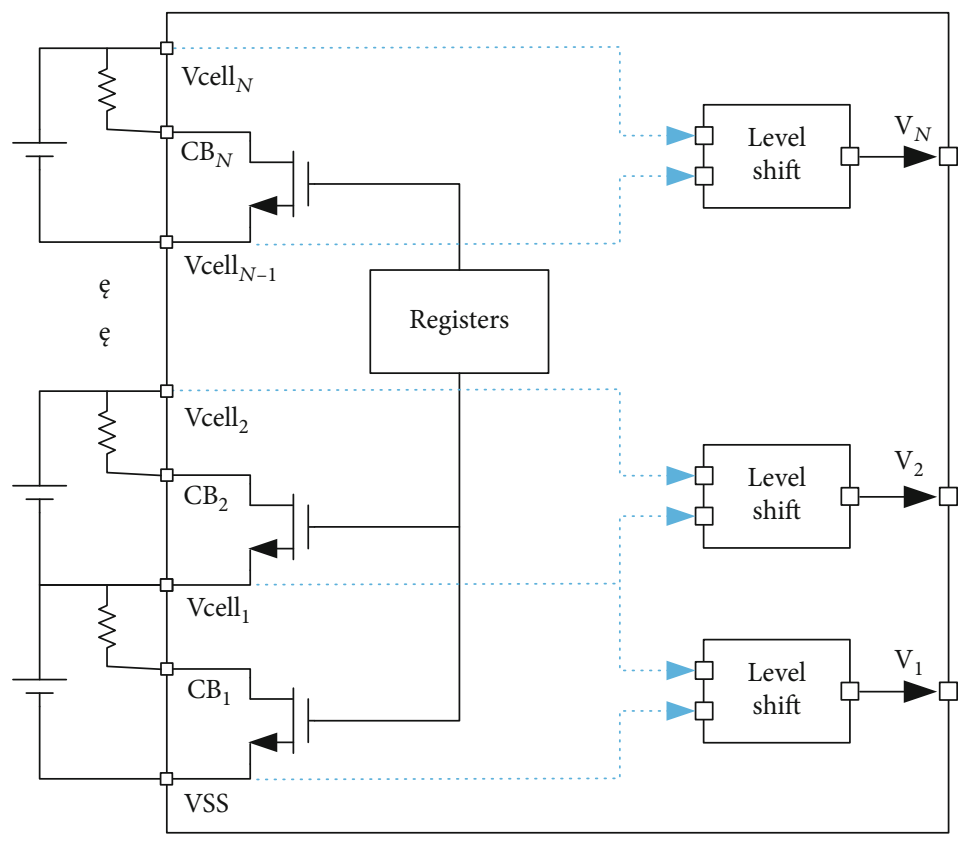

Figure 3: Cell balancing and batteries' voltage level shift circuits.

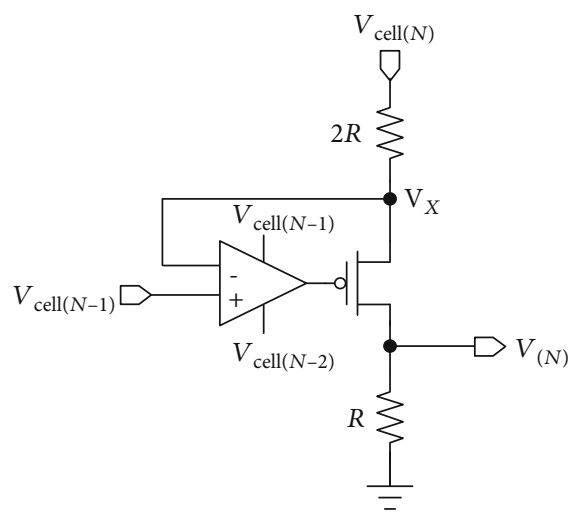

FIgURE 4: Battery cell voltage sampling circuit.

means that there is no actual current flowing from this node. Therefore, parasitic resistor $R_{\mathrm{P}}$ will not have an effect on the sampling accuracy. However, cell 15's anode has a current $I_{b}$ flowing from it, generating a voltage drop $I_{b} R_{\mathrm{P}}$ in this parasitic resistor, which makes the sampling of cell 15 and cell 16 not accurate. In order to cancel this current, a dummy op-amp is added, as shown in Figure 6. Using these methods, the current consumed by those op-amps in sampling circuits will not affect the precision of battery cells' voltage sampling.

3.2. Charging and Discharging Current Sampling. As shown in Figure 7, a sensing resistor $R_{\text {sense }}$ is put in the charging and discharging path. When charger or load is connected to the battery pack, there is a current flowing through the resistor, generating a voltage which can be sampled by the IC's pin "current sense." This voltage signal can be selected to the internal SAR ADC and be converted, and the digital code of current amplitude is obtained. The $R_{\text {sense }}$ is normally set as
$500 \mathrm{~m} \Omega$. With $0.2 \mathrm{mV}$ ADC resolution, the effective current sensing accuracy can be $0.4 \mathrm{~mA}$.

3.3. Temperature Sampling. A constant current generated by a bandgap flows through a diode-connected PNP bipolar transistor. Since the base-emitter voltage has a negative temperature coefficient, we can use this $V_{\text {be }}$ to detect internal temperature. As shown in Figure 8, a bipolar transistor's base-emitter voltage is directly connected to a comparator, which can output a warning flag when internal temperature is higher than the set threshold for a certain time. In addition, this $V_{\text {be }}$ can also be selected to the input of internal SAR $\mathrm{ADC}$ to be converted, and a digital output of internal temperature can be obtained.

Furthermore, this IC has inputs prepared to detect external temperature. Users can connect a thermal resistor with a constant resistor to generate a voltage which represents the external temperature.

3.4. 15-Bit Self-Calibrated SAR ADC. In modern application, high-precision control becomes increasingly important. Therefore, it is necessary that the IC provides an internal analog-to-digital converter to detect required signal. Some previous works [2] provide several integrated parallel ADCs so that the measurements can be synchronized. The measurements can be faster in this way, but it occupies too much area of the IC. In this work, therefore, a communal SAR ADC is provided to detect all the voltages in sequence.

The reference voltage of $\mathrm{ADC}$ is $2.5 \mathrm{~V}$, which means that the ADC needs to achieve a resolution of $0.2 \mathrm{mV} / 2.5 \mathrm{~V}=1$ / 12500 at least. It is true that a 14-bit SAR ADC can already achieve a resolution of $1 / 2^{14}=1 / 16384$. However, considering the deviation between simulation and tests, a 15-bit SAR ADC is selected. The structure of 15-bit SAR ADC is shown in Figure 9. The actual circuit of SAR ADC has 


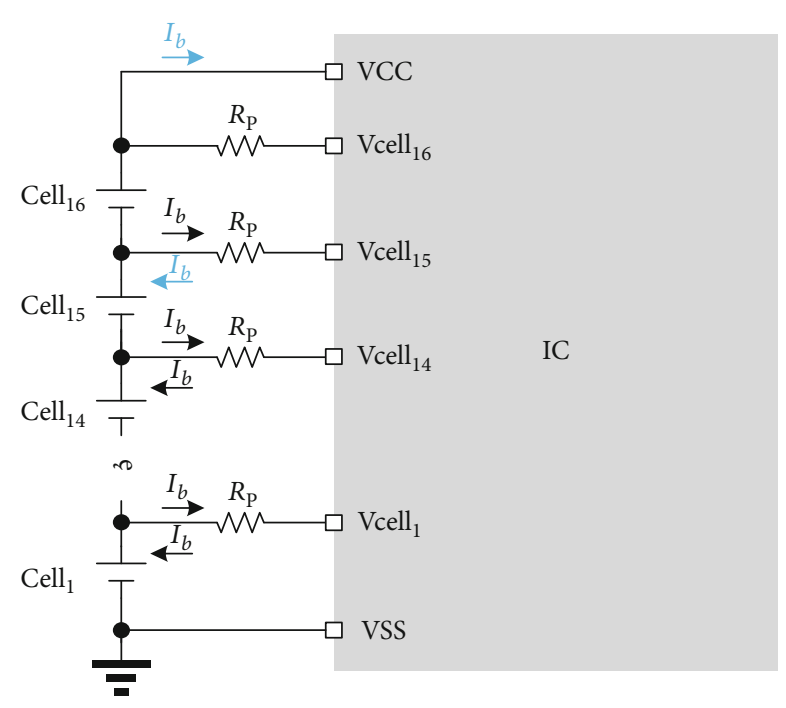

FIGURE 5: Current extracted by the amplifiers in the sampling circuit.

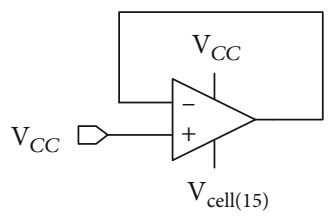

Figure 6: Dummy op-amp.

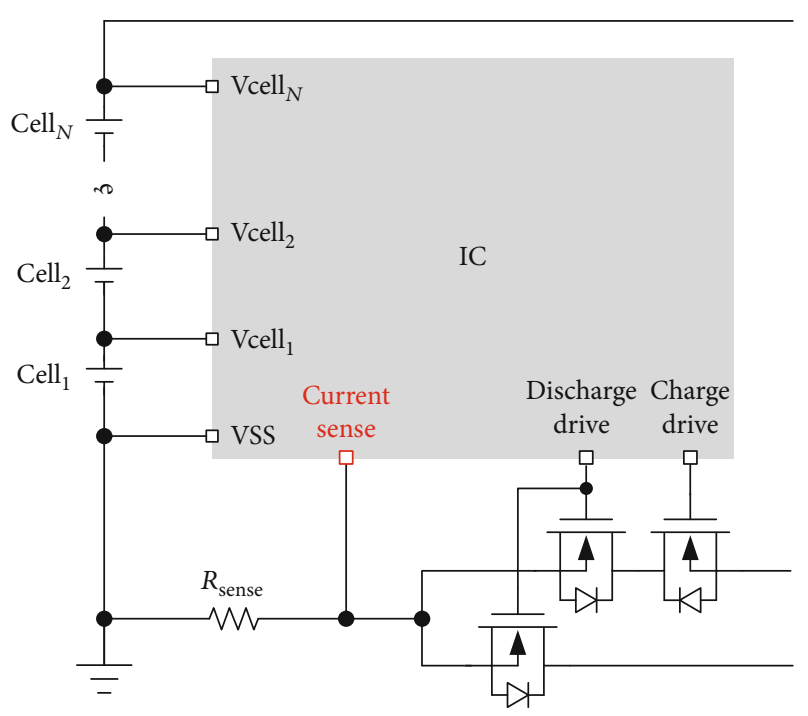

Figure 7: Current sampling circuit.

differential structure. For the convenience of description, this paper only gives the demonstration of a single side. In the practice of the battery management system, it is possible that negative voltage needs to be measured. For example, charging current is detected by a sampling resistor. Under this circumstance, the current flows from the negative electrode of the battery cell. One side of the sampling resistor is connected to the negative electrode of the lowest battery, and the voltage of another end is used to calculate the current. Therefore, a negative voltage needs to be converted. Under this circumstance, an extra capacitor is connected in shunt with the capacitor array, whose value is half of the capacitor of MSB. During the tracking mode, a lower plate of the extra capacitor is connected to ground and is switched to $V_{\mathrm{REF}}$ once ADC enters holding mode. Since the voltage at the positive input of the comparator is equal between the beginning and the end of the hold mode, the electric charge contributed by the extra capacitor will make the detected voltage higher than the real value by $1 / 4 V_{\mathrm{REF}}$. Thus, when processing negative voltage, the ADC will perform the above operation and obtain a digital code whose corresponding value equals the original voltage plus $1 / 4 V_{\mathrm{REF}}$. Through this method, the largest charging current $I_{\text {Charge,max }}$ that the IC can handle is $1 /$ ( $\left.4 V_{\mathrm{REF}} R_{\text {sense }}\right)$. With a $500 \mathrm{~m} \Omega$ sensing resistor, $I_{\text {Charge,max }}$ is 1.25 A. In practice, users can use a smaller sensing resistor to support a larger charging current.

In order to achieve the goal of high precision, a selfcalibration algorithm is proposed, realized by an auxiliary 13-bit capacitor array shown in Figure 9. This auxiliary capacitor array can be used to calibrate the input offset voltage of a comparator and mismatches of capacitors in the main array. The calibration process is completed automatically when ADC powers on. First, during the calibration of input offset voltage of a comparator, the bottom plate of the main capacitor array is connected to a constant voltage, and the auxiliary array samples a $0 \mathrm{~V}$ differential input voltage to operate a SAR conversion, thus achieving a 13-bit digital output, which can represent the input offset voltage of a comparator. Second, during the calibration of the capacitors' mismatch, what is wanted to obtain is the error of every bit's actual weight $w_{i}$ and its ideal weight. However, the ideal weight of the $i^{\text {th }}$ bit can be seen as $2^{i-1}$, which is theoretical and cannot be represented in the practical circuit. In practice, the deviation of the $i^{\text {th }}$ bit's $w_{i}$ weight and the sum of those lower bits' weight $\sum_{j=1}^{i-1} w_{j}$ are obtained first; then, the error code is calculated by an iteration algorithm. All the calibration code is stored in internal registers. During conversion, these codes are read in real time, controlling the auxiliary array to operate correspondingly to calibrate the error charge of the main array. Hence, the internal SAR ADC can achieve a high resolution.

\section{Other Circuits and Designed Algorithms}

4.1. Protection Circuit Design. Another highly significant function of a power management system is protection. In this work, the IC can detect different abnormal conditions and respond correspondingly. Possible abnormal conditions include the following: charging or discharging overcurrent, battery cells' overvoltage, and internal and external overtemperature. Protection circuitry is shown in Figure 10. For example, during charging operation, if the IC detects that discharging current magnitude exceeds the set threshold for a time long enough, it can be considered that the discharging overcurrent occurs. Consequently, the IC will shut down the discharging MOSFET to cut off the discharging path. 


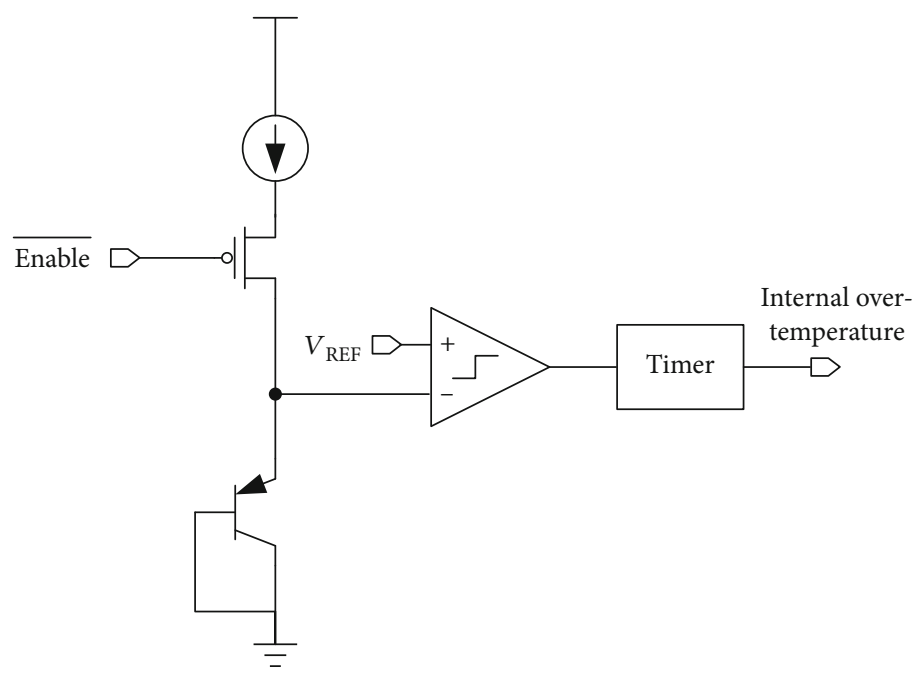

Figure 8: Internal temperature sampling circuit.

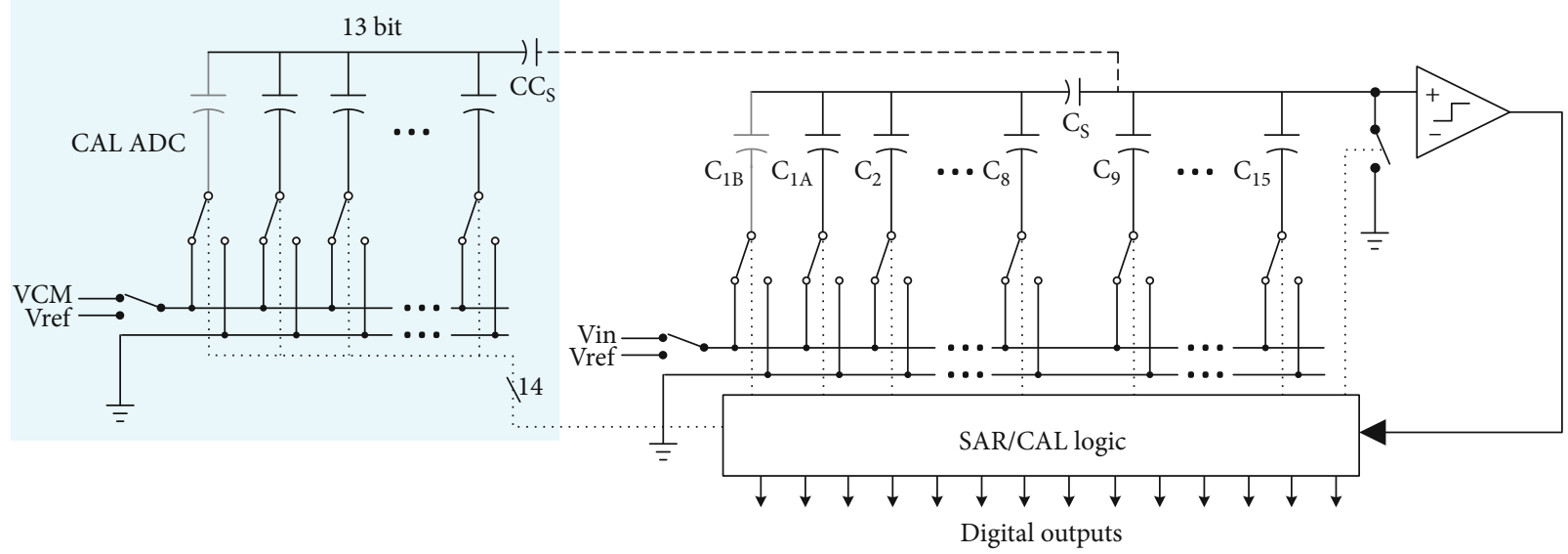

FIgURE 9: Internal 15-bit self-calibrated SAR ADC.

The delay time $( \pm 10 \%$ accuracy $)$ and judgement voltage thresholds $(0.2 \mathrm{mV}$ accuracy) of every abnormal condition can be adjusted through the $\mathrm{I}^{2} \mathrm{C}$ interface. Those circuitries to provide the reference clock and reference voltage are trimmed, thus guaranteeing the accuracy of delay time and threshold voltage.

As shown in Figure 10, there are two back-to-back $N$ -MOSFETs in the charging path and a single MOSFET in the discharging path. The back-to-back $N$-MOSFETs are necessary. If there is only one FET in the charging path, as shown in Figure 11, when the voltage of battery cells $V_{\text {Battery }}$ is lower than the charger's voltage $V_{\text {Charger }}$, the voltage of FET's source is $V_{\text {Battery }}-V_{\text {Charger }}$, which is negative. Then, the FET cannot be turned off even if the gate's voltage "CFET" is set to zero.

On the contrary, in Figure 10, the pin DFET controls M1 and M2, while CFET controls M3. DFET can provide both the pull-up and pull-down capability, while CFET can only provide pull-up capability. Thus, when a user needs to cut off both the charging and discharging paths, CFET is set to ground, which means that the gate to source voltage $V_{\mathrm{GS}}$ of
M1 and M2 is zero. Since the CFET has no pull-down capability, it is disconnected from M3, making the $V_{\mathrm{GS}}$ of M3 discharged form $R_{\mathrm{g}}$. Even if the voltage of M3's source is negative, the $V_{\mathrm{GS}}$ of $\mathrm{M} 3$ can still be discharged to zero. This guarantees reliable cut-off of the charging and discharging path.

4.2. Cell Voltage Balancing. During the processing of the battery pack, due to variance of physical volume, internal impendence, and thermal situation, the individual cells' voltages may drift apart over time [6]. Without the function of cell balancing, some battery cells' voltage can be higher than others; thus, there can be a situation where some cells are already fully charged or even over charged, while others are still not fully charged. However, the charger will be cut off only if all the cells are fully charged, which means that some cells will be charged continuously after being fully charged, which can cause an irreversible damage to a Li-on battery. As a result, the algorithm of battery cells' balancing is introduced, which maximizes the effective energy stored in the battery pack and extends the battery's life. 


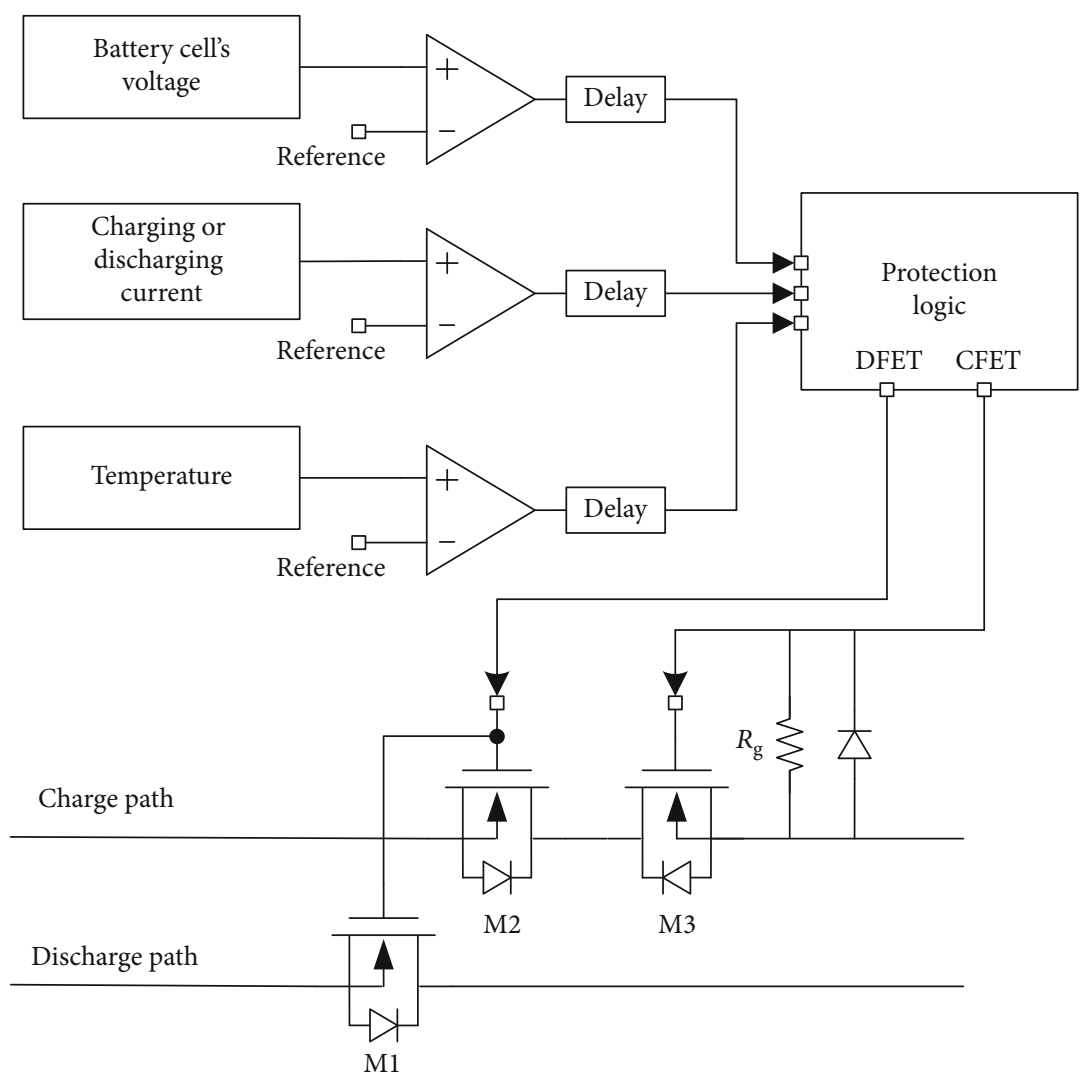

FIGURE 10: Protection circuit diagram of battery cells' voltage, charging and discharging current, and temperature.

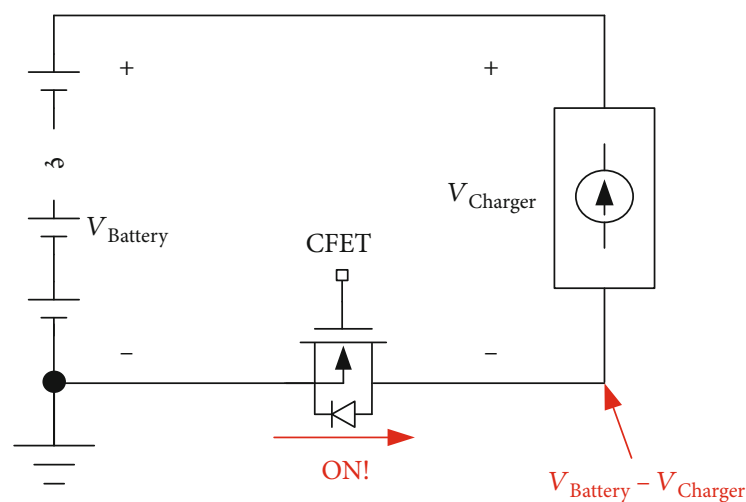

FIGURE 11: The simplified circuit if one FET is applied in the charging path.

In this work, the IC controls an external dissipative shunting resistor to consume the energy of those battery cells whose voltages are too high. Firstly, the IC gets the magnitude of all the battery cells' voltages from SAR ADC: $V_{n}=\{$ $\left.V_{1}, V_{2}, \cdots, V_{N}\right\}$. Then, the maximum value $V_{\text {max }}$ and minimum value $V_{\min }$ are picked out. If the value of $V_{\max }-V_{\min }$ is bigger than the set threshold $(100 \mathrm{mV})$, the battery pack can be considered scrapped. Otherwise, for four battery cells with the highest voltage, the corresponding CBN pins output high level to turn on the MOSFET, which connects the external resistor to the specific cells. Thus, the resistor will consume extra energy from those cells whose voltages are higher. With the charging or discharging going on, after a period of time, the energy consumed by the external resistor can make those cells' voltages drop faster or increase more slowly, thus bringing all the cells back to balance by repeating the above step.

4.3. SOC Estimation. It is indispensable to estimate the available energy left in the battery pack accurately in the practical use, since the system's tolerance range is needed to make corresponding arrangements. The most widely used metrics to measure that is State of Charge (SOC), which is normally defined as the ratio of its current capacity $Q(t)$ to the nominal capacity $Q_{n}$ [7]. $Q_{n}$ represents the maximum charge which can be stored in the battery. Accordingly, SOC can be formulated as

$$
\operatorname{SOC}(t)=\frac{Q(t)}{Q_{n}}
$$

4.3.1. Conventional Methods. The commonly used methods to estimate SOC include the following: Open Circuit Voltage (OCV) method, Coulomb counting method, internal impedance measurement method $[8,9]$, and intelligent algorithms, etc. [10]. The Coulomb counting method is easy to conduct, thus being widely embedded in BMS ICs. It suffers, however, from inaccurate initial SOC value and accumulated errors. Meanwhile, although the OCV method's algorithm is very simple, the accurate relationship between SOC and OCV remains difficult to measure. Besides, the intelligent 


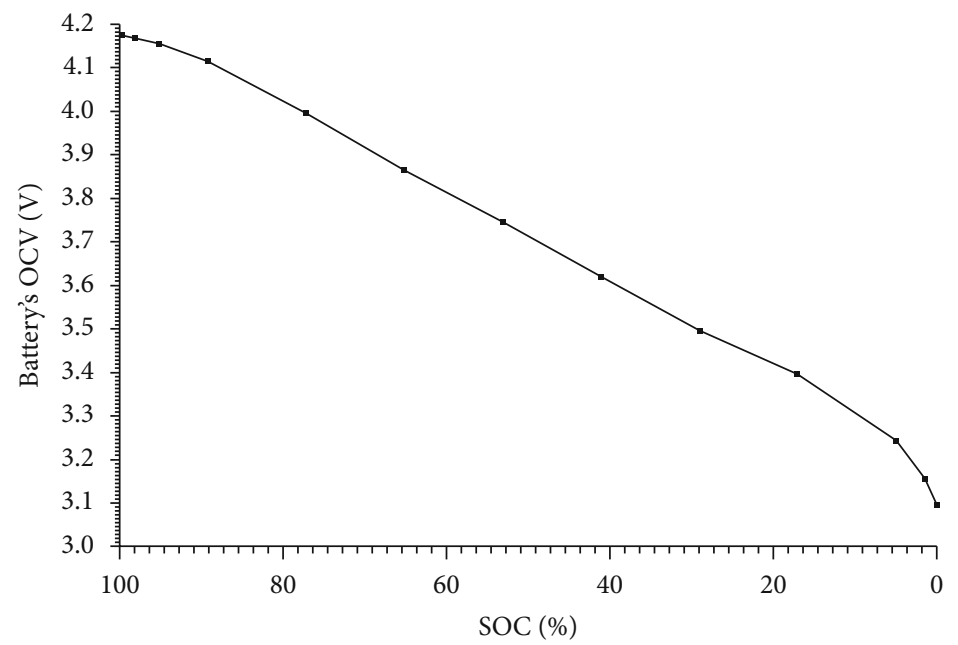

Figure 12: Test result curve of the battery's OCV vs. SOC.

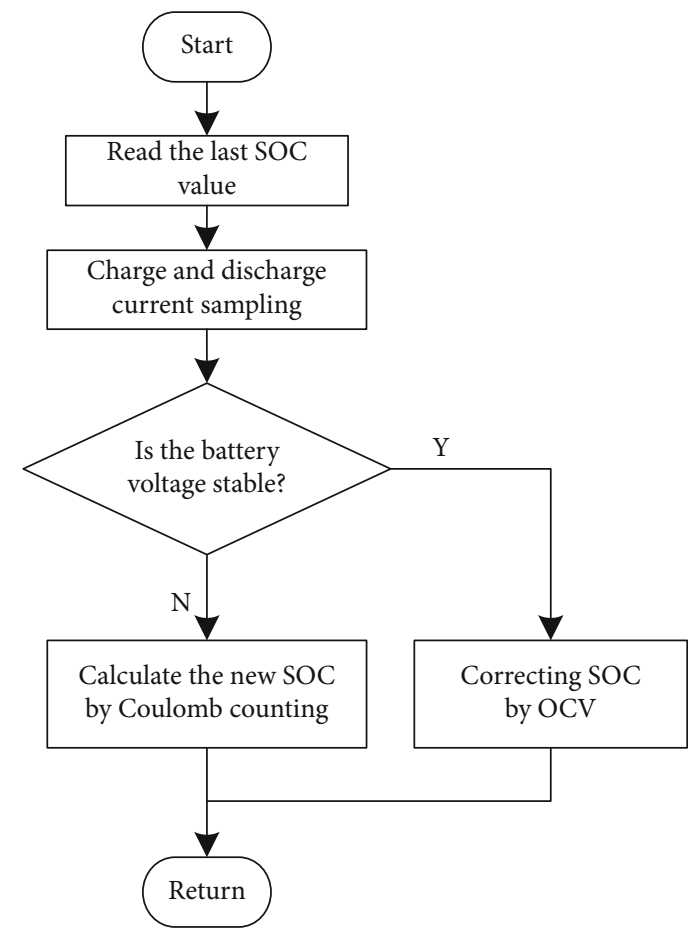

FIGURE 13: Flowchart of the SOC estimation algorithm.

algorithms include artificial neural networks, machine learning, etc. These intelligent algorithms need extensive test data and high-performance computing unit, which is not available in some applications.

(1) OCV Method. There is a relationship between SOC and OCV of a battery [10], which can be derived from experimental data. Taking the $18650 \mathrm{Li}$-ion battery as an example, we used a constant current source to charge it from empty to full. Every ten-minute charging must be followed with a rest time period of two hours, ensuring that the battery's voltage was stable. Repeat this operation until the battery is fully

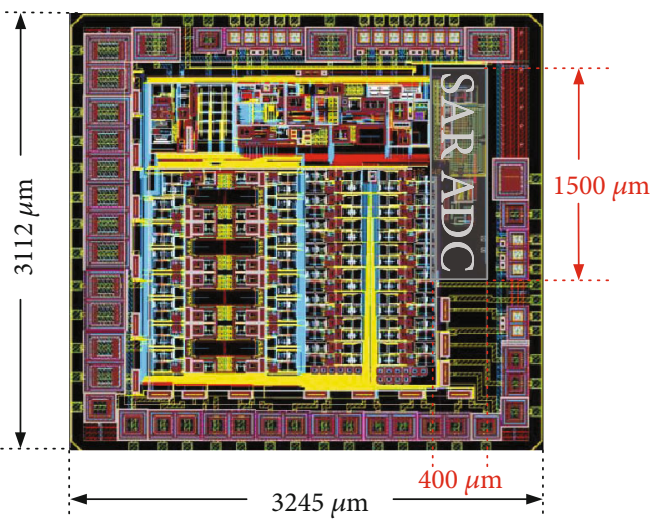

FIgURE 14: Layout of the complete IC.

charged. The procedure is just the same in the discharging test. After multiple experiments and averaging, the relationship between SOC and OCV can be demonstrated in Figure 12 according to our test data. As a result, the value of SOC can be adjusted by curve fitting using premeasured data, with error not exceeding $0.1 \%$ in the experiment. However, the voltage across the battery is not necessarily equal to the actual OCV during operation; instead, it varies with the working current's variation. Also, the battery needs a long time to stabilize after charging or discharging operation, which can be an hour or even longer. As a consequence, the OCV method is inaccurate in most cases and cannot acquire data in real time.

(2) Coulomb Counting Method. If the battery's current is constant during a time period $\Delta t$, the change of $Q(t)$ can be calculated by 


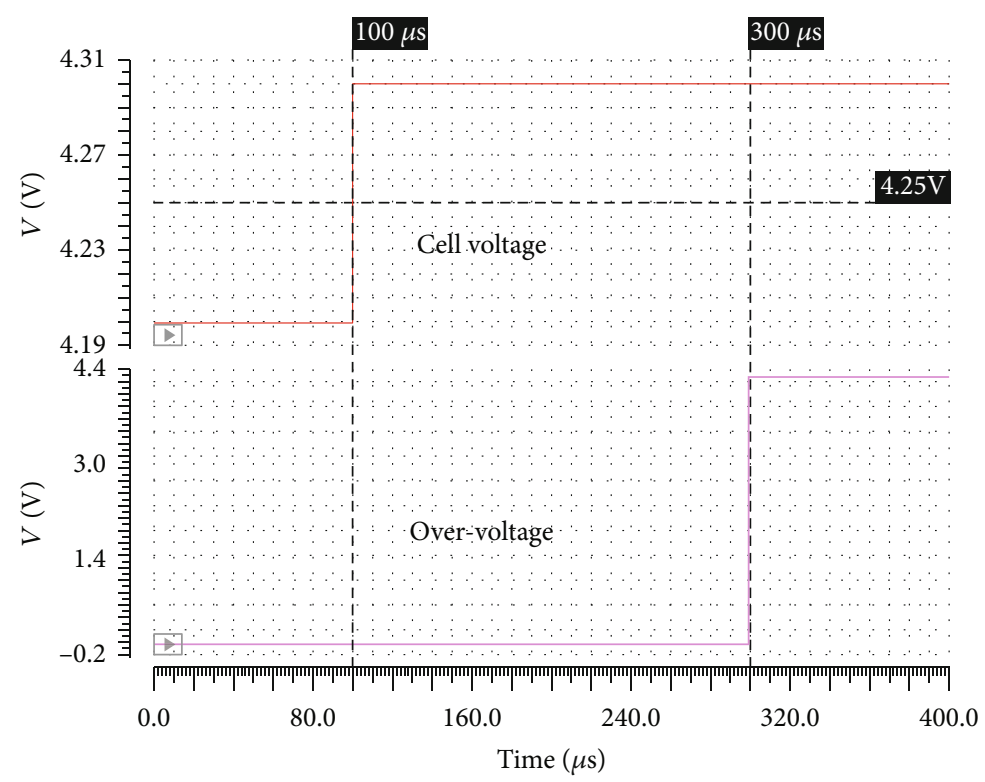

FIGURE 15: Waveform of battery cell overvoltage.

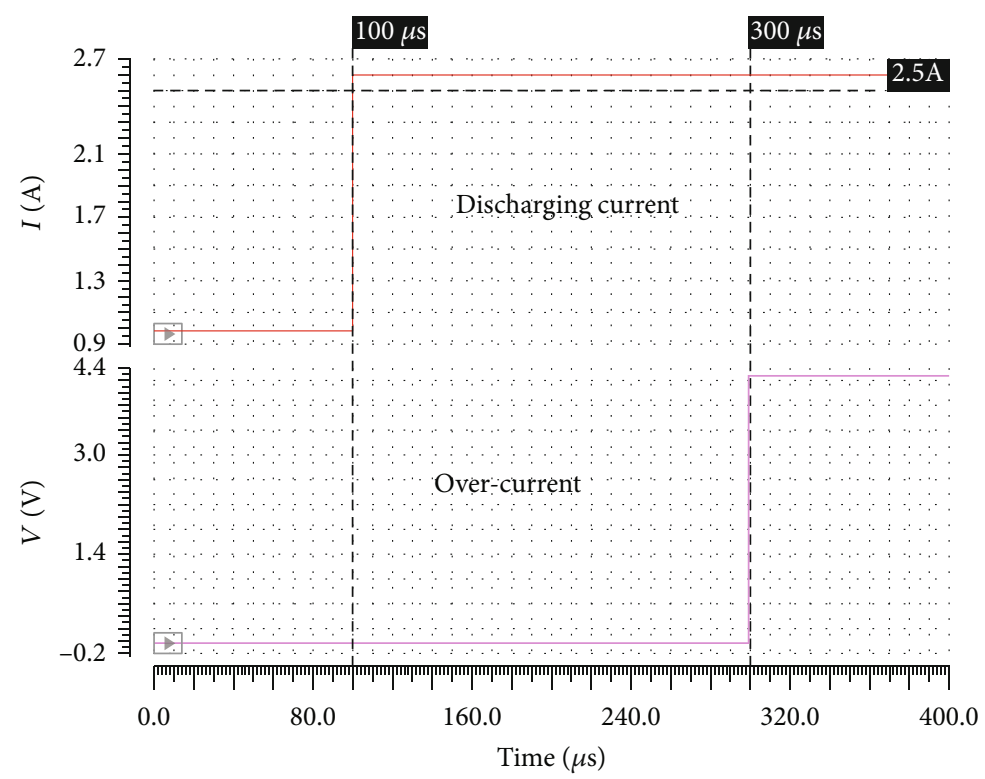

FIGURE 16: Waveform of discharging overcurrent.

Furthermore, (5) can be derived:

$$
Q(t)=\int I d t
$$

This is the so-called Coulomb counting method.

In order to facilitate the algorithm's operation, the Coulomb counting method can be modified by the following equation:

$$
\operatorname{SOC}(t)=\operatorname{SOC}(t-1)+\frac{I(t)}{Q_{n}} \cdot \Delta t .
$$

In a word, during continuous operation of the battery system, current magnitude can be estimated periodically through $\mathrm{ADC}$, which is used to update the SOC value regularly. 


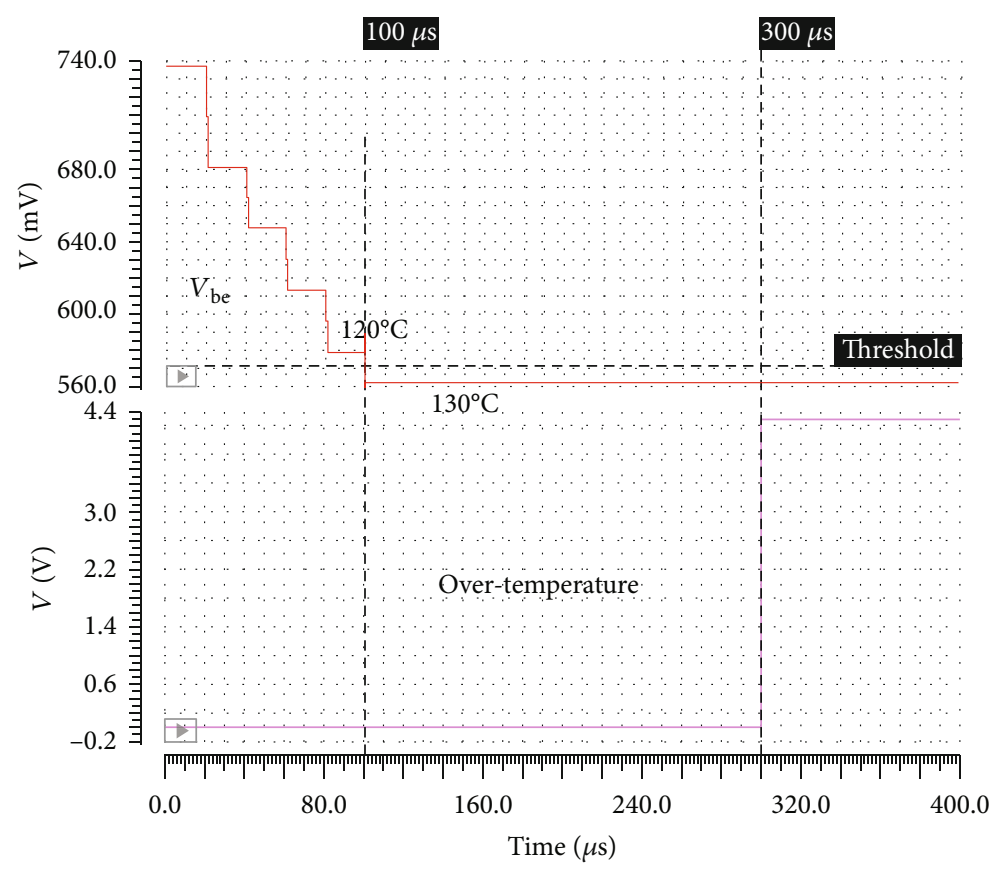

FIGURE 17: Waveform of overtemperature.

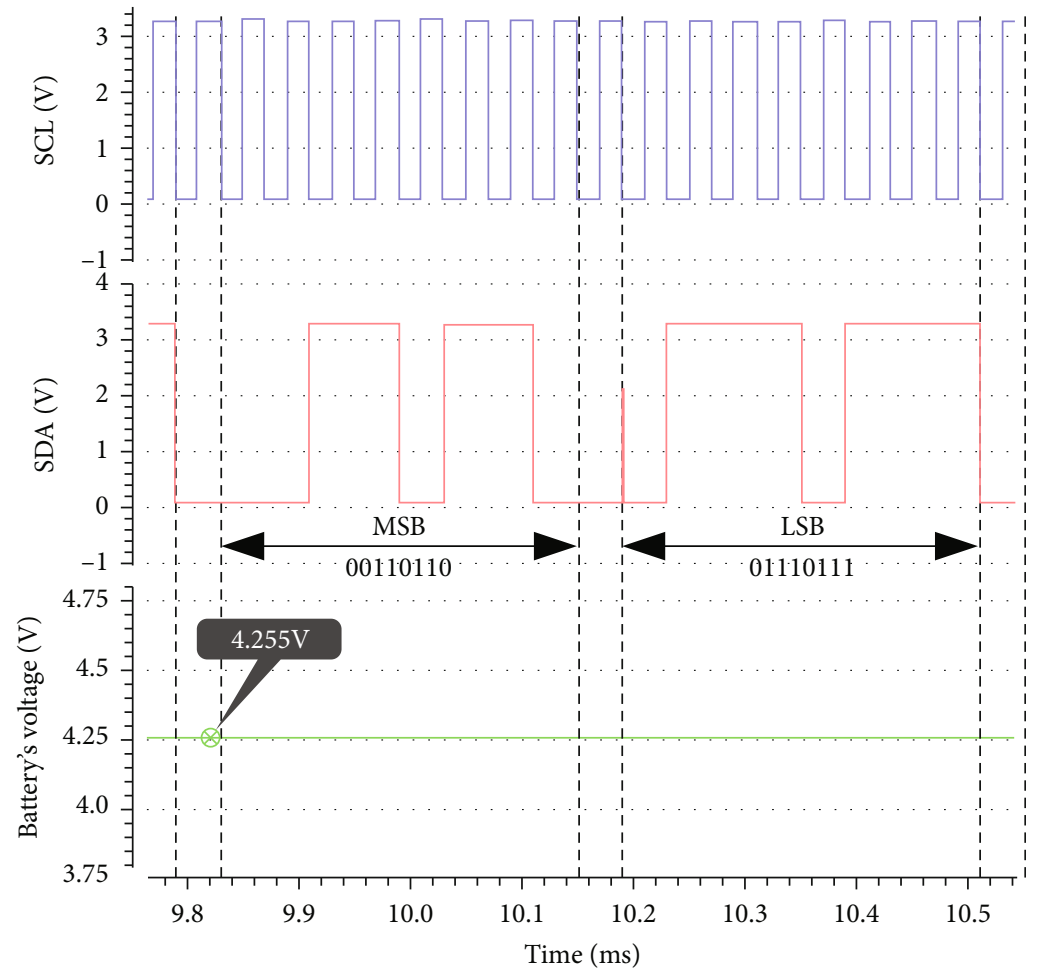

Figure 18: Waveform of $\mathrm{I}^{2} \mathrm{C}$ when reading codes from ADC.

4.3.2. Proposed Method. In this work, OCV and Coulomb counting methods are synthesized, which combines the advantages of both methods. Therefore, this IC is able to estimate the SOC value in real time with high precision.

The magnitude of battery cells' voltage (OCV) is available directly through SAR ADC. At the same time, charging or discharging current magnitude used for Coulomb counting can be detected by a sampling resistor in the charging and discharging path. Voltage drop through the sampling resistor is processed by $\mathrm{ADC}$ to calculate the current's magnitude.

During operation, the IC reads the last SOC value at the beginning of each calculation cycle and updates the SOC 

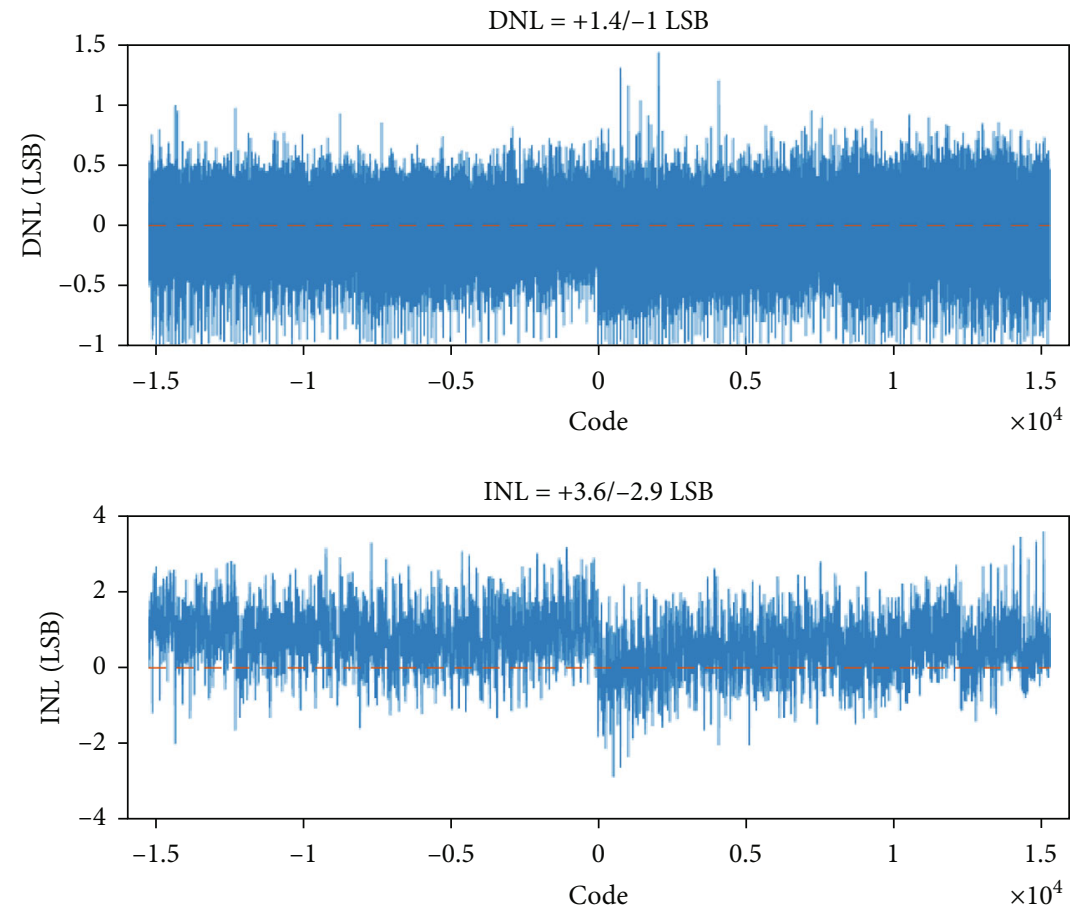

FIGURE 19: Static characteristics of ADC.

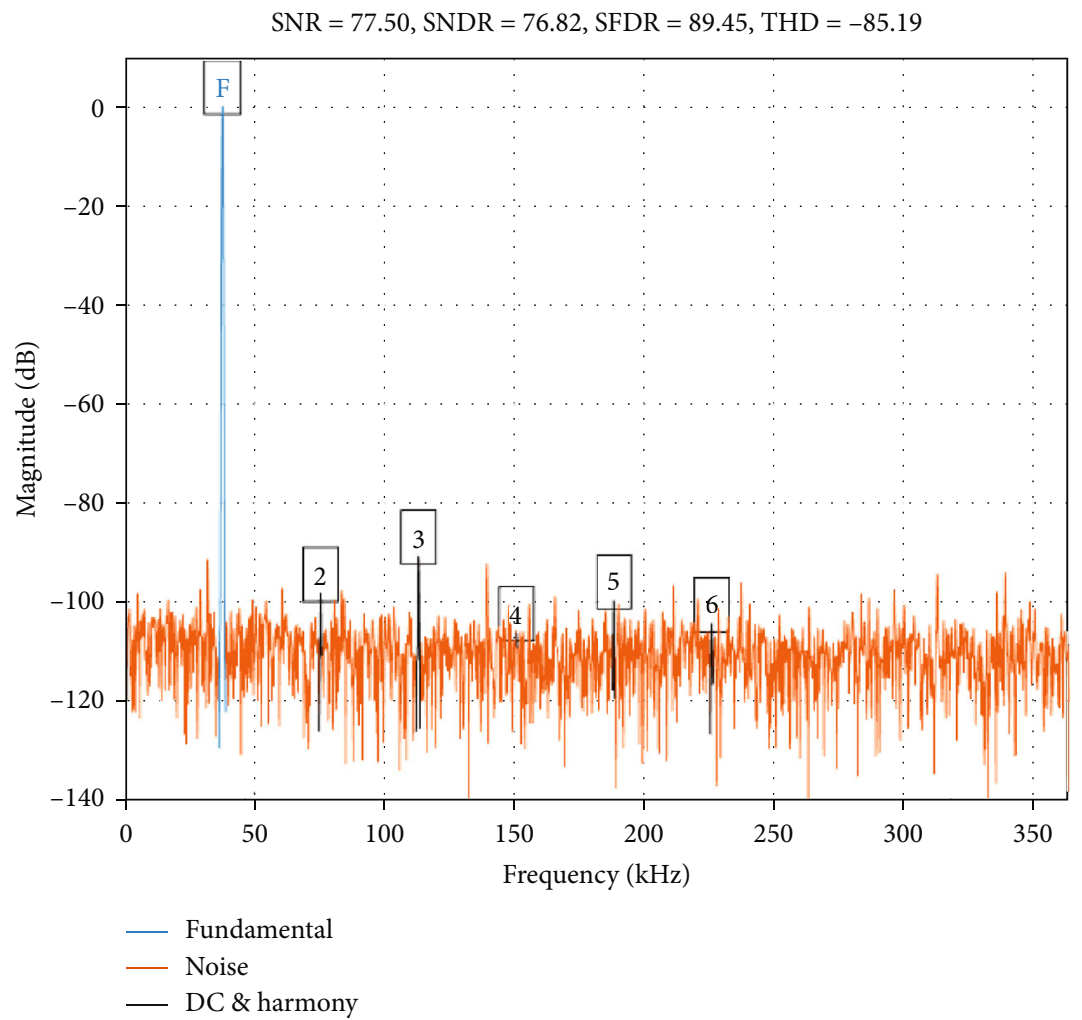

FIgURE 20: Dynamic characteristics of ADC.

value by the Coulomb counting method in real time. Besides, it can identify whether the system is working or not and has a time counter recording the period when the system is pow- ered down. If this time is long enough, which presents that the batteries' terminal voltage is stable and nearly equal to OCV, the IC will adapt the OCV method to adjust the SOC 
TABLE 2: Comparison of this work with previous ICs.

\begin{tabular}{lccc}
\hline Property & This work & {$[3]$} & {$[4]$} \\
\hline Quiescent current & $800 \mu \mathrm{A}^{*}$ & $950 \mu \mathrm{A}$ & $2 \mathrm{~mA}$ \\
ADC resolution & $<0.2 \mathrm{mV}$ & Total error $<2.2 \mathrm{mV}$ & $<1.1 \mathrm{mV}$ \\
Comm. & No external components & External MOS drivers & External MOS drivers \\
\hline
\end{tabular}

${ }^{*}$ The quiescent current is estimated via simulations.

TABLE 3: Breakdown of the quiescent current.

\begin{tabular}{lc}
\hline Module & Quiescent current \\
\hline SAR ADC & $310 \mu \mathrm{A}$ \\
Reference & $120 \mu \mathrm{A}$ \\
Sampling circuit & $260 \mu \mathrm{A}$ \\
Others & $110 \mu \mathrm{A}$ \\
\hline
\end{tabular}

TABle 4: Performance summary of the prototype.

\begin{tabular}{lc}
\hline Parameter & Value \\
\hline Process & $180 \mathrm{~nm}$ CMOS process \\
LDO 1 (for internal use) & $5 \mathrm{~V}$ \\
LDO 2 (for internal use) & $12 \mathrm{~V}$ \\
LDO 3 (for external use) & $3.3 \mathrm{~V}$ \\
SAR ADC & $15 \mathrm{bit}$ \\
Sampling precision & $0.21 \mathrm{mV}$ \\
SOC precision & $\pm 0.1 \% / \mathrm{h}$ \\
& Overvoltage \\
Protection functions & Overcurrent \\
& Overtemperature \\
Temperature range & $-40^{\circ} \mathrm{C} \sim 125^{\circ} \mathrm{C}^{*}$ \\
\hline
\end{tabular}

*The temperature range is just for functionality.

value using curve fitting, based on obtained data shown in Figure 12. After being restarted, the IC carries on the Coulomb counting operation. Thus, the system can obtain accurate SOC value in real time and avoid cumulative error caused by Coulomb counting. However, the data in Figure 12 is just a reference. The relationship between SOC and OCV will vary with time going on. That is to say if an accurate SOC value is demanded, the curve of SOC and OCV must be adjusted according to using time and environment. In order to verify this method by experiment, we selected an existing ADC chip with 15-bit accuracy to build a testing system. The OCV is tested using the same way in which the curve of the battery's OCV vs. SOC is obtained, and current is also detected to calculate the SOC value. By comparing the results of several experiments, the total estimation error will not exceed $0.1 \%$ within an hour. The algorithm's flowchart is shown in Figure 13.

\section{Results}

The IC was designed in a $0.18 \mu \mathrm{m}$ Bi-CMOS process: "DongBu-181aBD18BA," and the layout is shown in Figure 14. This IC's size is $3245 \mu \mathrm{m} \times 3112 \mu \mathrm{m}$.
The IC's overall functions are only verified by postsimulation. Postsimulation results demonstrate that the IC can detect all the abnormal situations and respond rapidly, generally by turning off the corresponding charging or discharging MOSFET. For example, the overvoltage time delay is set to $200 \mu \mathrm{s}$, and the cell's voltage exceeds the threshold of $4.25 \mathrm{~V}$ at $100 \mu \mathrm{s}$. Then, at $300 \mu \mathrm{s}$, the overvoltage warning bit is set high; meanwhile, the IC automatically cuts off the discharging path, as shown in Figure 15. Similarly, the discharging current exceeds the threshold of $2.5 \mathrm{~A}$ at $100 \mu \mathrm{s}$; then, at $300 \mu \mathrm{s}$, the overcurrent warning bit is set high, as shown in Figure 16.

Make the temperature vary with time, as shown in Figure 17. The overtemperature time delay is also set to $200 \mu \mathrm{s}$. When the temperature exceeds the threshold $125^{\circ} \mathrm{C}$ for $200 \mu \mathrm{s}$, the overtemperature indicator is set high and the IC will cut off the charging and discharging path.

Figure 18 shows the result when the IC chooses a battery's voltage of $4.255 \mathrm{~V}$ to perform analog-to-digital conversion and reads the obtained code from it. Considering the reference voltage of $2.5 \mathrm{~V}$ of $\mathrm{ADC}$, the obtained digital result is $2.1275 \mathrm{~V}$. This value is half of the chosen battery cell's voltage, indicating that it represents the actual magnitude of 4.255 V. The accuracy of ADC is verified.

The proposed self-calibrated SAR ADC has been fabricated and tested separately. The static characteristics and dynamic characteristics are given in Figures 19 and 20. The DNL is -1 to $1.4 \mathrm{LSB}$, and the INL is -2.9 to $3.6 \mathrm{LSB}$. The dynamic characteristics are tested in the 720 KSPS sampling rate and $37 \mathrm{kHz}$ input signal frequency. When input is half of the magnitude, SNDR is $76.82 \mathrm{~dB}$, from which we can deduce that in full input magnitude, SNDR is $82.84 \mathrm{~dB}$ and ENOB (effective number of bits) is 13.5 bit.

Table 2 provides a comparison of this work with similar ICs from industry. Table 3 provides the breakdown of the quiescent current. Table 4 provides a general summary of this work.

\section{Conclusion and Prospect}

In summary, a complete power management system IC with full integration, high precision, and high reliability for a battery pack which can monitor and protect the system is demonstrated, achieving lower application costs. The IC protects the battery from overvoltage, overcurrent, and overtemperature when charging and discharging with $0.2 \mathrm{mV}$ discrimination accuracy. With a SAR ADC integrated, the IC can get precise magnitude of each battery cell's voltage, the internal or external temperature, and charging or discharging current with $0.2 \mathrm{mV}$ voltage accuracy. The IC works with an external 
MCU, being able to perform battery cell voltages' balancing and to help users to get the SOC value with $0.1 \%$ estimation accuracy. After verification, the IC ensures safe operation of the system with the Li-ion battery pack. In following work, the MCU will be integrated with an analog front end, making it a fully integrated power management IC with intelligent self-control for the Li-ion battery pack.

\section{Data Availability}

The data used to support the findings of this study are available from the corresponding author upon request.

\section{Conflicts of Interest}

The authors declare that they have no conflicts of interest.

\section{Acknowledgments}

We thank the ICPES 2019 committee for receiving our former research paper [5], which can be retrieved in https:// ieeexplore.ieee.org/document/9105561. This work was supported by the Guangdong Province's Key R\&D Program, China (grant number 2019B010143002).

\section{References}

[1] N. Noda, "21st century cars and ICs," in 2000 IEEE International Solid-State Circuits Conference. Digest of Technical Papers (Cat. No.00CH37056), pp. 12-17, San Francisco, CA, USA, Febuary 2000.

[2] K. Kadirvel, J. Carpenter, P. Huynh, J. M. Ross, R. Shoemaker, and B. Lum-Shue-Chan, "A stackable, 6-cell, Li-ion, battery management IC for electric vehicles with 13, 12-bit $\Sigma \Delta$ ADCs, cell balancing, and direct-connect current-mode communications," IEEE Journal of Solid-State Circuits, vol. 49, no. 4, pp. 928-934, 2014.

[3] M. Up et al.et al., LTC6813-1 Multicell Battery Monitor Features $1-86$.

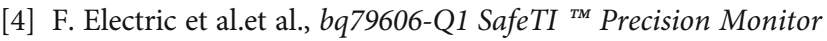
with Integrated Hardware Protector for Automotive Battery Pack Applications Initial Release, 2018.

[5] Y. Hao, J. Xi, and L. He, "A power management IC used for protection system of Li-ion battery packs," in 2019 IEEE 9th International Conference on Power and Energy Systems (ICPES), Perth, WA, Australia, December 2019.

[6] W. F. Bentley, "Cell voltage balancing considerations for lithium-ion battery systems," in The Twelfth Annual Battery Conference on Applications and Advances, pp. 223-226, Long Beach, CA, USA, January 1997.

[7] S. Sato and A. Kawamura, "A new estimation method of state of charge using terminal voltage and internal resistance for lead acid battery," in Proceedings of the Power Conversion Conference-Osaka 2002 (Cat. No.02TH8579), pp. 565-570, Osaka, Japan, April 2002.

[8] D. D. Lu, "A simple internal resistance estimation method based on open circuit voltage test under different temperature conditions," in 2018 IEEE International Power Electronics and Application Conference and Exposition (PEAC), pp. 1-4, Shenzhen, China, November 2018.
[9] J. Cao, N. Schofield, and A. Emadi, "Battery balancing methods: a comprehensive review," in 2008 IEEE Vehicle Power and Propulsion Conference, pp. 1-6, Harbin, China, September 2008.

[10] K. Lee, M. Dai, and C. Chuang, "Temperature-compensated model for lithium-ion polymer batteries with extended Kalman filter state-of-charge estimation for an implantable charger," IEEE Transactions on Industrial Electronics, vol. 65, no. 1, pp. 589-596, 2018. 